\title{
A INFLUÊNCIA DA COMPONENTE TRIBUTÁRIA NA DEFINIÇÃO DO MODELO CONSTITUCIONAL DE ATRIBUIÇÃO DOS RESULTADOS ECONÔMICOS NA EXPLORAÇÃO DO PETRÓLEO OFFSHORE NO BRASIL
}

\author{
Raymundo Juliano Feitosa ${ }^{1}$ \\ Marconi Costa Albuquerque ${ }^{2}$
}

RESUMO: Este trabalho analisa a influência tributária na definição do modelo constitucional de atribuição dos resultados econômicos da exploração do petróleo offshore, no Brasil. Além da abordagem constitucional do tema, destaca-se a participação dos entes federativos estaduais nas rendas da produção de petróleo, sua federalização e, em decorrência, a redução das rendas dos entes federativos subnacionais, implicando num movimento compensatório pela via da utilização de elementos de natureza tributária, tais como o extinto Imposto Único sobre Minerais e o regime constitucional especial de cobrança na origem do ICMS devido nas operações de combustíveis e derivados de petróleo.

Palavras-Chave: petróleo, royalties, tributação, constitucional, federação

\section{THE INFLUENCE OF TAX FEATURES ON CONSTITUTIONAL MODEL FOR THE ECONOMIC ALLOCATION RESULTS FROM OFFSHORE OIL EXPLORATION IN BRAZIL}

\begin{abstract}
This short study presents the tax influence on the definition of the constitutional model for the economic allocation results from offshore oil exploration in Brazil. Besides to the constitutional approach of the theme, this work focus on participation of the state entities in the incomes of petroleum production, its federalization process along several history periods. the consequent incomes reductions due to sub national entities and, finally, the compensatory movements using tax elements, such as the federal extinct tax on minerals or the special constitutional regime of collection at the origin of the ICMS due in petroleum fuels and other byproducts operations.
\end{abstract}

Key words: royalties, petroleum, off shore production, constitutional model, tax influence3

\footnotetext{
${ }^{1}$ Doutor em Direito pela Universidad Autonoma de Madrid. Professor dos cursos de Graduação, Mestrado e Doutorado em Direito da Universidade Católica de Pernambuco.

${ }^{2}$ Doutorando em Direito pela Universidade Católica de Pernambuco. Professor do Curso de Graduação em Direito da Universidade Católica de Pernambuco.
} 


\section{Raymundo Juliano Feitosa \& Marconi Costa Albuquerque}

\section{INTRODUÇÃO}

O presente trabalho versa sobre a questão do modelo constitucional de atribuição dos resultados econômicos da exploração do petróleo offshore no Brasil, tema que resvala para o plano infraconstitucional, naquilo que resta discutido, de forma mais detalhada e específica, no campo da política dos royalties.

Busca-se desenvolver o presente estudo a partir das premissas constitucionais pertinentes, que fundamentam a questão, procurando-se, igualmente, aliar tal enfrentamento a elementos de natureza histórica e tributário que, em última análise, nos remetem ao tema do federalismo fiscal e do orçamento, discussão que passa não somente pelo viés da despesa, é claro, mas, igualmente, pelo viés da receita, e que constitui, em última análise, a questão de interesse central desse trabalho.

Não se pretende, contudo, descer, aqui, à análise mais profunda dos conflitos que, atualmente, fundamentam as demandas entre os distintos entes federativos brasileiros, em face da política de partilha dos royalties decorrentes dos resultados econômicos da exploração de óleo na região da plataforma continental brasileira e que hoje estão judicializados, em sede de Ações de Inconstitucionalidade (ADIs 4016-ES, 4917-RJ e 4920-SP), propostas perante o STF.

O fato é que a discussão dessa questão nos termos dos limites da disputa regional por recursos (LOUREIRO, 2012), envolveria, certamente, um esforço bem maior, pois a discussão segundo esse viés, demandaria outro tipo de análise e uma abordagem teórica de outra monta, que extrapola os limites teóricos do presente estudo. Portanto, quando muito, é aqui apresentada uma breve digressão acerca da disputa regional pelos recursos advindos dos resultados econômicos da exploração de petróleo offshore, visando, tão somente, embasar a questão dos fundamentos da constitucionalização dos resultados econômicos do petróleo.

O que se busca, na verdade, é desenvolver uma análise que passa pela observação das rupturas que ao longo das modificações trazidas pelos diversos textos constitucionais, impregnados, quiçá, pela evolução do sistema tributário incorporado ao texto hoje vigente, da Constituição da República de 1988, aponte para a constitucionalização dos resultados econômicos dos royalties do petróleo e sua repercussão no campo federativo, tudo isso desenvolvido a partir de um plano de criticidade necessária, na medida em que comungamos da ideia esposada por Raymundo Juliano, de que “a Constituição é o estatuto jurídico do político” (FEITOSA, 2003). 
Parte-se, primeiramente, do seguinte "problema”: Existe algum viés tributário, seja na política do ICMS, seja na política do extinto Imposto Único sobre Minerais, que possa subsidiar a ideia da constitucionalização dos resultados econômicos da exploração offshore de petróleo no Brasil, repercutindo na política dos royalties, e que atribua aos Estados produtores (Rio de Janeiro, Espírito Santo e São Paulo), prioritariamente, a principal fatia desses recursos?

A abordagem de tal problema tem como "hipótese” a ideia de que, restando comprovada a existência de alterações extraordinárias da política do ICMS relativa à indústria do petróleo, que desbordem do leito normal das regulações gerais desse tributo, no que tange ao seu "regime de cobrança no destino”, ou algum impacto que possa resultar da análise acerca das razões da extinção do Imposto Único sobre Minerais, então deverão restar definidos mais do que indícios de que a constitucionalização dos resultados econômicos da exploração do petróleo advindo da produção offshore brasileira traria, de forma implícita, um componente tributário indiscutível na sua formulação.

Por fim, tem-se como “objetivo geral”, verificar comprovações de que a constitucionalização dos resultados econômicos da exploração do petróleo originados da produção offshore teria sido construída a partir de um viés de natureza tributária, relacionada, sobretudo, atualmente, com a política do ICMS, e outrora com a política do extinto regime dos impostos únicos, com clara repercussão no âmbito federativo.

A discussão aqui travada, tem no volume dos resultados econômicos derivados da produção brasileira offshore, sua principal motivação, posto que tal fato constitui a razão do conflito federativo, quando o tema passa a ser considerado a partir da perspectiva da sua partilha entre os entes federativos subnacionais do Estado Federal brasileiro, que mesmo não sendo a opção do autor no tocante ao objetivo maior da pesquisa, não deixa de constituir uma das suas principais balizas.

Aqui reside, portanto, o centro nervoso de toda essa discussão, seu viés econômico, aspecto que atrai a atenção dos entes federativos subnacionais brasileiros, tornando o tema num dos mais relevantes na perspectiva atual dos resultados econômicos e da política dos royalties do petróleo.

Em segundo plano, mas não menos relevante, a importância do presente estudo se funda, igualmente, nas desigualdades constatadas entre os diversos entes federativos brasileiros. 
Resta por demais óbvio, que as desigualdades observadas entre os entes federativos subnacionais brasileiros assumem papel de destaque, na medida em que afloram questões como a da partilha dos resultados econômicos do petróleo.

Não é sem razão, que Bauman (BAUMAN, 1998) afirma que a "questão da desigualdade, seja entre os estados ou dentro da mesma sociedade, atinge, nos tempos pósmodernos, proporções que o mundo de há pouco tempo, confiante em sua habilidade de autorregular-se e autocorrigir-se, parecia ter deixado para trás uma vez por todas”.

O trabalho encontra-se dividido em 04 partes, a saber: uma introdução na qual são tecidos comentários gerais de apresentação do tema, um segundo item que versa sobre a importância e a perspectiva constitucional dos resultados econômicos da exploração offshore no Brasil; um terceiro item que trata da relação da constitucionalização dos resultados econômicos decorrentes da produção de petróleo offshore com a política tributária do ICMS e o regime tributário dos extintos impostos únicos e, finalmente, uma conclusão onde se arremata os principais pontos hauridos da presente pesquisa.

No mais, deixe-se registrado que a atual discussão, aqui encetada, atendendo a um corte metodológico próprio, escolhido pelo autor, volta-se apenas para a observação dos resultados econômicos oriundos da produção offshore, qual seja, a questão posta nos limites de territorialidade da plataforma continental e da zona economicamente exclusiva.

Daí e por tudo, destaca-se a importância da análise do critério que, em última análise, teria levado à constitucionalização da temática dos resultados econômicos da produção do petróleo offshore, pano de fundo desse trabalho, pois o seu entendimento, como o que se pretende aqui demonstrar, tendo por base elementos de índole tributária, calcados na política do ICMS e do extinto Imposto Único sobre Minerais, poderá descortinar variáveis interessantes, lançando luzes sobre o entendimento da própria questão da partilha desses recursos econômicos entre os distintos entes federativos subnacionais do Estado brasileiro.

\section{A CONSTITUCIONALIZAÇÃO DOS RESULTADOS ECONÔMICOS}

\section{DA EXPLORAÇÃO OFFSHORE DO PETRÓLEO NO BRASIL E SUA IMPORTÂNCIA}

A importância do tema em comento se faz presente a partir da observação de vários elementos de naturezas econômica e jurídica, fundamentalmente. 


\section{A INFLUÊNCIA DA COMPONENTE TRIBUTÁRIA NA DEFINIÇÃO DO MODELO CONSTITUCIONAL DE ATRIBUIÇÃO DOS RESULTADOS ECONÔMICOS NA EXPLORAÇÃ̃O DO PETRÓLEO OFFSHORE NO BRASIL}

A partir da perspectiva econômica, em primeiro lugar, convém salientar, que a produção de petróleo no Brasil, teve início com a exploração onshore, a partir do conhecimento haurido dos estudos geológicos desenvolvidos no âmbito das bacias sedimentares, em ambiente continental e que constituiu, durante algum tempo, a primeira trincheira da exploração de petróleo em solo pátrio.

Com o “aparente esgotamento" do ambiente geológico das bacias sedimentares continentais, restou aberta uma nova fronteira de pesquisa de óleo e gás, na ambiência offshore, provocando uma alteração de rumo nos investimentos da Petrobrás, redirecionados, agora, para o campo geológico dos modelos marinhos.

O sucesso econômico dessa nova opção política e estratégica e que provocou o redirecionamento dos investimentos da Petrobrás, das áreas continentais (onshore) para as áreas da plataforma continental (offshore), torna-se evidente com a comprovação de novas e importantes descobertas, implicando, pois, no aumento substancial das nossas reservas de óleo e gás, incorporadas ao acervo da estatal de petróleo, possibilitando, ademais, um claro incremento da produção.

A título de comprovação desse resultado exitoso, os dados da figura abaixo (Crescimento das Reservas de Petróleo - fonte ANP, Agência Nacional de Petróleo), mostram claramente a curva de evolução das reservas de petróleo brasileiras, e, o mais importante, que tal fato coincidiu com a mudança da política de exploração adotada pela Petrobrás, priorizando a exploração off-shore, a partir de 1995.

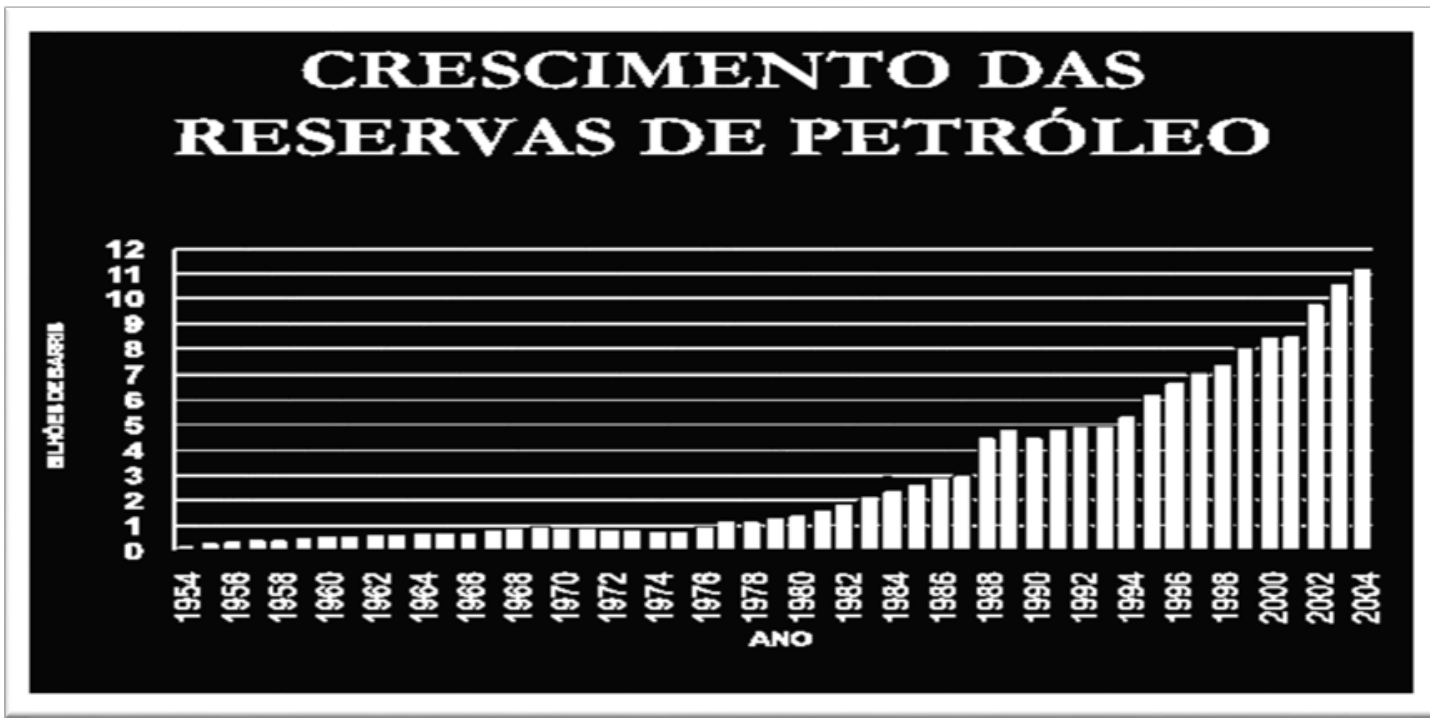




\section{Raymundo Juliano Feitosa \& Marconi Costa Albuquerque}

Observe-se, na figura antes mencionada, que o crescimento exponencial das reservas de petróleo a partir de 1995, aproximadamente, coincide, de um modo geral, com a flexibilização do regime do monopólio constitucional da União, em relação ao petróleo, resultado dos reflexos da Emenda Constitucional 09/95.

Apenas como registro de mais uma componente econômica do tema, convém destacar que as atividades envolvendo petróleo e gás natural, representam uma das principais fontes de receitas do país, tendo movimentado, apenas em 2010, mais de 500 bilhões de reais, conforme afirmam Gustavo Brigagão e Bruno Lyra (BRIGAGÃO \& LYRA, 2015), em artigo de obra coordenada pela jurista Mizabel Derzi (DERZI, 2015).

Finalmente, convém lembrar que, em momentos de escassez de receitas e em face da dificuldade da ampliação da matriz de arrecadação de tributos, pois, no caso brasileiro, a carga tributária já se queda em níveis insuportáveis, a busca, pelo Estado, de fontes alternativas de receitas, sempre é perseguida, de sorte que a geração de recursos advindos dos royalties decorrentes da produção de petróleo constitui, de modo irretocável, uma fonte de receitas altamente desejável, o que, do ponto de vista econômico, coloca em destaque a importância do tema em comento.

Analisando o tema, agora, a partir da perspectiva jurídica, não se pode negar a profunda contribuição, definida em sede constitucional, decorrente do advento da Emenda Constitucional nº 09, de 1995, que alterando a redação originária do Artigo 177, da Constituição Federal de 1988, trouxe à luz uma modificação significativa do regime de pleno monopólio na exploração de petróleo no Brasil, possibilitando à União, desde então, delegar os esforços de exploração, antes centralizados na Petrobrás, para os entes privados ou públicos, nos termos da lei, assim entendido, uma exploração desenvolvida sob as regras de aplicação do "regime de concessão" (Lei 9.478/1997) e, posteriormente, quando do advento do pré-sal, conforme as regras do “regime de partilha de produção” (Lei 12.351/2010).

Independentemente de qualquer juízo de valor, acerca do aspecto positivo, ou não, da repercussão, na prática, da Emenda Constitucional no 09, de 1995, os dados retratados pela figura acima (Crescimento das Reservas de Petróleo), mostram, de forma evidente, a coincidência do crescimento exponencial das reservas de óleo, a partir do advento dessa incorporação modificativa do texto constitucional que deu nova redação ao Artigo 177, da Carta da República de 1988. 


\section{A INFLUÊNCIA DA COMPONENTE TRIBUTÁRIA NA DEFINIÇÃO DO MODELO CONSTITUCIONAL DE ATRIBUIÇÃO DOS RESULTADOS ECONÔMICOS NA EXPLORAÇÃO DO PETRÓLEO OFFSHORE NO BRASIL}

Tudo isso, portanto, aponta, é claro, para a perspectiva do aumento potencial das receitas advindas dos resultados econômicos da produção de petróleo, cuja pauta de regulamentação, em sede constitucional, restou explicitada pelo Artigo 20, § $1^{\circ}$, da Constituição Federal de 1988, sobretudo a partir do desenvolvimento do incremento da exploração em ambiente offshore, dinamizada, pois, pela flexibilização do monopólio constitucional do petróleo da União, nos termos dados pela nova redação do já referido Artigo 177, da Carta da República de 1988 e, convenhamos, pela opção política da Petrobrás em redirecionar, a partir daí, os rumos da pesquisa.

Muito embora, sob a perspectiva constitucional, a questão do tratamento dos bens minerais, inclusive o petróleo e, bem assim, a modelagem da distribuição dos resultados econômicos advindos da produção desses bens, esteja definida, cabe destacar que, em nenhum momento, o texto constitucional brasileiro de 1988, nem os anteriores a ele, faz menção à expressão royalty, para sinalizar a respeito dos resultados econômicos oriundos da produção de petróleo, seja ela desenvolvida onshore ou decorrente do ambiente offshore (SCAFF, 2014), discussão essa que se trava, na verdade, de forma detalhada, na esfera infraconstitucional.

Diferentemente do que possa parecer, a temática da constitucionalização dos resultados econômicos oriundos da produção de petróleo, remonta, no contexto temporal, a uma época distante e que coincide com os primórdios da discussão das questões pertinentes relativas à indústria do petróleo no Brasil.

Do alto da perspectiva histórica, a constitucionalização dos resultados econômicos da produção do petróleo nos remete, pois, a tempos que remontam, na verdade, à criação da empresa estatal brasileira de petróleo, a PETROBRÁS.

Estamos falando, pois, dos idos da década de 50, quando, pela Lei 2004 de 03.10.1953, foi criada a PETROBRÁS, no período do governo do Presidente Getúlio Vargas e instituída, então, a "Política Nacional do Petróleo".

Cabe ressaltar, todavia, que a constitucionalização dos rendimentos econômicos advindos da produção offshore de petróleo no Brasil, calcada sob o preceito da titularidade dominial da União, bem como a previsão da partilha desses resultados pelos entes federativos subnacionais, se faz notar, de modo mais consolidado, a partir da Constituição da República de 1988 (LOUREIRO, 2012), pautada que foi tal questão pelo seu Artigo 20, $\S 1^{\text {o }}$, que 


\section{Raymundo Juliano Feitosa \& Marconi Costa Albuquerque}

expressamente trouxe à baila a referência às balizas da “compensação” e “participação”, esses sim, conceitos referidos textualmente pelo legislador constitucional de 1988, a saber:

“São bens da União:

$(\ldots .$.

$\mathrm{V}$ - os recursos naturais da plataforma continental e da zona econômica exclusiva;

$(\ldots .$.

IX - os recursos minerais, inclusive os do subsolo;

$(\ldots .$.

$\S 1^{\circ}$ É assegurada, nos termos da lei, aos Estados, ao Distrito Federal e aos Municípios, bem como a órgão da administração direta da União, participação no resultado da exploração de petróleo ou gás natural, de recursos hídricos para fins de geração de energia elétrica e de outros recursos minerais no respectivo território, plataforma continental ou zona econômica exclusiva, ou compensação financeira por essa exploração. (negritos nossos)

A análise dos resultados econômicos advindos da produção do petróleo a partir dessa perspectiva constitucional, nos coloca diante da apreciação das temáticas relativas ao próprio direito de percepção dessas receitas, bem como no que diz respeito ao regime aplicável de partilha dos referidos resultados econômicos decorrentes da produção, entre os entes federativos subnacionais, mormente no caso da exploração offshore.

Sem verticalizar a discussão, o fato é que, os Estados Federados, segundo Gustavo Kaercher (LOUREIRO, 2012)

“afastados da propriedade das jazidas de petróleo em 1941 (Decreto-Lei 3236/41), ...... lograram obter participação (somente pecuniária) na produção de petróleo, primeiramente nos seus territórios (1953) e posteriormente na plataforma continental adjacente (1985), depois de um período durante o qual tal participação beneficiava apenas a União Federal (1969-1985)”.

A definição do direito de participação dos entes subnacionais (Estados e Municípios) nos resultados econômicos decorrentes da exploração do petróleo deixa de ser, em 1988, uma simples previsão de direito ex lege, tanto no que diz respeito às ocorrências no território continental, como na plataforma continental e zona economicamente exclusiva, para ser um direito ex constitutione (LOUREIRO, 2012).

A principal questão que se apresenta, neste ponto, reside em saber como equacionar a dúvida, algo complicada, acerca da possibilidade da atribuição de direito à percepção dos 


\section{A INFLUÊNCIA DA COMPONENTE TRIBUTÁRIA NA DEFINIÇÃO DO MODELO CONSTITUCIONAL DE ATRIBUIÇÃO DOS RESULTADOS ECONÔMICOS NA EXPLORAÇÃ̃O DO PETRÓLEO OFFSHORE NO BRASIL}

resultados econômicos decorrentes da produção de petróleo offshore para aqueles entes subnacionais que não são proprietários do referido bem, como bem destaca Gustavo Kaercher (LOUREIRO, 2012).

Em que pese a previsão inserida na Constituição da República de 1988, em seu artigo 20, § $1^{\circ}$, destinando os resultados econômicos da produção do petróleo offshore a Estados e Municípios, ideia posteriormente regulamentada a partir das noções de "Estados produtores” e Municípios inseridos na “área de abrangência da atividade exploratória”, definição essa que é dada por critérios geográficos e geodésicos pouco claros, relacionados com a projeção ortogonal dos limites de seus territórios, não são poucas as divergências interpretativas acerca do significado real dessa norma constitucional, mormente quando a questão envolve a produção offshore.

Do lado dos denominados “entes produtores”, a parcela dos royalties do petróleo destinada a tais entes federativos seria de natureza compensatória e defendida não com base em critérios de propriedade, questão que traz um agravante todo especial quando a exploração se dá no ambiente offshore, mas em critérios relativos aos ônus assumidos com a implantação de políticas de infraestrutura, bem como em face da repercussão de impactos ambientais e socioeconômicos suportados por esses entes, decorrentes desse tipo de atividade de exploração de óleo e gás, sem descurar, ainda, do fato de que o texto constitucional do artigo 20 , $\S 1^{\circ}$, da Constituição Federal de 1988, em vigor, acima referido, é, para os que advogam o direito à compensação dos Estados e Municípios, bastante claro nesse mister, constituindo qualquer esforço de interpretação, uma tarefa desnecessária (BICHARA \& MONTENEGRO, 2015).

Já com relação aos demais entes federativos “não produtores” é advogada a tese de que o critério de definição da "participação” e “compensação” em face dos resultados econômicos decorrentes da produção de petróleo offshore deveria passar, obrigatoriamente, pelo critério da propriedade, da titularidade dominial, e segundo os que adotam esse viés não haveria espaço para a reinvindicação dos entes federativos ditos não produtores ou que se situem na esfera de abrangência das atividades de exploração, tratando-se, aqui, de simples aplicação da Convenção de Montego Bay, de 1982, sobre os direitos do mar (COELHO, 2015).

Demonstrado, pois, o modelo constitucional de atribuição dos resultados econômicos da exploração do petróleo offshore no Brasil, bem como a previsão da destinação de uma parcela desses resultados econômicos para os entes subnacionais do Estado Federal brasileiro, resta 
tentar costurar, agora, toda essa observação, com uma análise que leve em conta a existência de possíveis elementos tributários que possam respaldar o posicionamento do legislador constituinte de 1988 na montagem do sistema de inserção dos entes federativos subnacionais (Estados e Municípios) no processo de “compensação” e “participação” previsto no Artigo 20, $\S 1^{\circ}$, da Carta da República e, até mesmo, servir de justificativa para o entendimento da(s) razão(ões) que teria(m) contribuído na definição desse sistema intrincado de divisão dessas receitas provenientes da atividade da exploração do petróleo.

\section{A RELAÇÃO DA CONSTITUCIONALIZAÇÃO DOS RESULTADOS ECONÔMICOS DA PRODUÇÃO DO PETRÓLEO OFFSHORE COM A POLÍTICA DO ICMS E O REGIME DOS EXTINTOS IMPOSTOS ÚNICOS FEDERAIS}

A discussão acerca da inserção constitucional dos resultados econômicos advindos da produção do petróleo off shore é algo que deve ser analisado, tendo como baliza, a evolução histórica da natureza jurídica da propriedade mineral.

Por outro lado, no tocante ao modelo de distribuição dos resultados econômicos da produção de petróleo, mormente aquele derivado da exploração off shore, tema que nos interessa mais de perto, há que se levar em conta o regime de rendas e os elementos de natureza tributária que podem apontar para as razões adotadas, em vários momentos, pelo legislador constitucional, na definição do modelo apropriado ao tratamento jurídico da questão.

Convém, ainda, destacar que em relação ao petróleo, muito embora o tratamento da matéria tenha sido, e continue a ser, objeto, no campo constitucional, de uma abordagem conjunta com os recursos minerais em geral, na esfera infraconstitucional, a temática do petróleo adquiriu, a partir de 1938, um tratamento especializado e diferenciado, no qual se sobressai a figura da concessão petrolífera e a vedação de jazidas privadas de petróleo (LOUREIRO, 2012), mantendo até então um tratamento geral coincidente com aquele dos demais recursos minerais.

Em primeiro lugar, passemos, pois, a analisar a questão, em face da evolução da natureza jurídica da propriedade das minas e jazidas no Brasil e o seu reflexo no regime de rendas.

Nem sempre a apropriação dos resultados econômicos da exploração mineral, incluindo o petróleo, em particular, hoje atribuída à União, favoreceu o Estado nessa perspectiva.

E isso se deve ao fato de que a natureza jurídica da propriedade das minas e jazidas sofreu, ao longo do tempo, alteração em seu significado, assumindo, por vezes, uma natureza pública e, por vezes, uma natureza privada. 


\section{A INFLUÊNCIA DA COMPONENTE TRIBUTÁRIA NA DEFINIÇÃO DO MODELO CONSTITUCIONAL DE ATRIBUIÇÃO DOS RESULTADOS ECONÔMICOS NA EXPLORAÇÃO DO PETRÓLEO OFFSHORE NO BRASIL}

A questão da normatização jurídica das minas e jazidas, no Brasil, incluindo o petróleo, passa, primeiramente, pelos períodos da história colonial e imperial, em nosso país, com repercussão nos seus respectivos regimes de rendas.

Fato é que, em momentos distantes da história, a propriedade mineral no Brasil, teve a sua exploração desenvolvida, primeiramente, na condição de bens da Coroa, sob a tutela do “regime jurídico regaliano”, durante todo o período colonial, ou foi explorada, ainda, mais adiante, como bem público, não mais da Coroa, mas da nação, no período imperial, submetendo-se, naquela oportunidade ao “regime jurídico dominial”, ocasiões essas nas quais as rendas da produção mineral eram definidas segundo o critério da titularidade dominial das minas ou jazidas, fossem elas da Coroa ou da Nação, como dispõe Lauro Lacerda Rocha (ROCHA, 1983).

Nos vários períodos republicanos, subsequentes, a análise da questão deve ser realizada a partir dos textos normativos das Constituições de 1891, 1934, 1937, 1946, 1967 e, mais recentemente, pela Constituição de 1988, bem como pelos respectivos Códigos de Mineração vigentes em cada um desses períodos de balisamento constitucional, nos quais se observa um claro movimento de publicização da propriedade mineral ao longo do tempo.

Prova dessa evolução do regime jurídico da exploração mineral, incluindo aqui o petróleo, pode ser notada a partir da primeira Carta Republicana, quando as jazidas e minas em território nacional passaram a ser reguladas pelas normas do "regime jurídico da acessão", apregoado pela Constituição de 1891 e explicitado, de forma expressa, em seu Artigo 72, onde se destacava a prevalência do proprietário do solo, como elemento de definição da titularidade dominial das riquezas minerais (VIVACQUA, 1942), a saber:

“Art. 72

(.....)

$\S 17$.

(.....)

As minas pertencem aos proprietários do solo, salvas as limitações que forem estabelecidas por lei a bem da exploração deste ramo de indústria.”

Com a atribuição da propriedade das minas e jazidas aos proprietários do solo, segundo previsão da Constituição de 1891, acima referida, passou-se a admitir a possibilidade da 


\section{Raymundo Juliano Feitosa \& Marconi Costa Albuquerque}

existência de minas públicas ou privadas, dependendo, é claro, da natureza jurídica do proprietário do solo.

Na esfera das minas privadas, o proprietário do solo era livre para explorar jazidas minerais, sem ter que assumir o ônus de pagar qualquer quantia ao Estado pela exploração do bem mineral, situação que restou assim regulamentada a partir do Código de Mineração de 1921, concebido à luz dos ditames da Constituição de 1891.

Após ter sido assegurada a propriedade mineral ao governo da Coroa (período colonial) e o governo do Império (período imperial), a exploração das minas e jazidas passou a se submeter, desde a Constituição de 1891, à tutela do "regime jurídico civil da acessão”, com destaque para a "prioridade do proprietário do solo" e, posteriormente, mantido o caráter privado da propriedade mineral, à tutela do "regime jurídico da concessão e autorização”, na forma da lei, trazido à baila pela Constituição de 1934 (Artigo 119) e reafirmado pelos textos constitucionais de 1937 (Artigo 143, caput) e 1946 (Artigos 152 e 153), tendo o Poder Público deixado, então, de receber qualquer retribuição a título de compensação financeira pela exploração das minas e jazidas minerais privadas (LOUREIRO, 2012).

A renda auferida pelo Estado à título de compensação financeira pela exploração das minas e jazidas minerais só passa a ser considerada a partir do momento em que a propriedade mineral passa a ser tida como de natureza pública e os recursos minerais são incluídos no rol de bens do Estado, como é o caso ora vigente, conferido à pessoa da União. É o que passou a ocorrer com o previsto na atual Constituição Federal de 1988, quando os recursos minerais, em geral, e o petróleo, em particular, passaram a ser considerados como bens da União, surgindo daí a geração dos royalties sobre minério e petróleo.

No caso específico do petróleo, sua definição como propriedade de natureza pública e bem da União, surge a partir das modificações que datam de 1938, trazidas no bojo dos Decretos-Leis 366, 395 e 538, que submetia a exploração de óleo e gás ao regime de “concessão petrolífera”, de competência federal, e retirava do campo privado tais jazidas.

Tal fato, qual seja, a divisão das jazidas em públicas e privadas, com a prevalência desse último tipo, acrescido à ideia do estabelecimento da Federação e a ausência do Poder Público no resultado da exploração dos bens minerais, abriu, por outro lado, espaço para o exercício do poder de tributar dos entes federados, segundo entendimento de Gustavo Kaercher (LOUREIRO, 2012). 


\section{A INFLUÊNCIA DA COMPONENTE TRIBUTÁRIA NA DEFINIÇÃO DO MODELO CONSTITUCIONAL DE ATRIBUIÇÃO DOS RESULTADOS ECONÔMICOS NA EXPLORAÇÃ̃O DO PETRÓLEO OFFSHORE NO BRASIL}

Com a previsão da primeira Carta republicana, que passou a considerar a possibilidade da caracterização da propriedade estadual das minas e jazidas situadas em seu território, vários Estados passaram a tributar a produção mineral, valendo-se do conhecido imposto de importação, de vez que não existia, na ocasião, a definição de uma competência tributária específica incidente sobre a propriedade mineral (BALEEIRO, 1974).

Observe-se que durante todo o período anterior ao da publicização da propriedade mineral nas mãos da União, regime ora vigente, nos termos da previsão do legislador constituinte de 1988, contida no bojo do artigo 20, da Carta da República, que surge de forma tímida, no que tange tão somente à definição da competência da União para legislar sobre a exploração dos recursos minerais, a partir da Constituição de 1934, a questão das rendas sobre a produção mineral foi sempre objeto de um tratamento não homogêneo, tendo em vista que os Estados ainda não estavam destituídos da propriedade mineral, nem, tampouco, desprovidos da competência para legislar supletivamente sobre as minas e jazidas, passando cada um a legislar em causa própria.

Não obstante a constituição da Petrobrás (1953) marque um momento importante na questão do petróleo no Brasil, a discussão de toda essa temática surge de modo mais especificado no campo infraconstitucional, nos idos de 1938, quando a atividade de petróleo assume, por decisão do governo de Getúlio Vargas, uma especialidade regulatória e institucional toda própria (Decretos-Leis 366, 395 e 538 de 1938), desligando-se do campo geral da mineração, como vinha até então sendo tratada e já centralizando nas mãos da União (Departamento Nacional da Produção Mineral) o instrumento básico da “concessão de lavra”, bem como outras tantas competências de naturezas regulatória e fiscalizatória.

O tema particular dos resultados econômicos advindos da produção do petróleo, por outro lado, como já referimos anteriormente, remonta ao tempo de criação da empresa estatal de petróleo brasileira, Petrobrás (Lei nº 2004 de 1953), ocasião em que restou determinada a participação dos Estados e Municípios produtores, entes de direito público, na composição societária da novel empresa estatal criada para levar a cabo os esforços da exploração de petróleo no território nacional.

Convém destacar, nesse sentido, que o Artigo 10, da Lei 2004 de 1953, deixava expressa essa possibilidade, a saber:

“Artigo 10 


\section{Raymundo Juliano Feitosa \& Marconi Costa Albuquerque}

$\S 3^{\circ}$ A União transferirá, sem ônus, aos Estados e Municípios em cujos territórios existem ou venham a ser descobertas jazidas e minas de petróleo de rochas betuminosas e pirobetuminosas e de gases naturais, respectivamente $8 \%$ (oito por cento) e $2 \%$ (dois por cento) das ações relativas ao valor atribuído a essas jazidas e pelo qual sejam incorporadas ao capital da Petrobrás no ato de sua constituição ou posteriormente” (negrito nosso).

A referida participação societária assegurada em lei aos Estados e Municípios produtores foi defendida à época como o resultado da perda de arrecadação tributária (LOUREIRO, 2012).

Em que pese a natureza não tributária dos resultados econômicos da produção do petróleo, entende-se, todavia, que o modelo constitucional de distribuição dos resultados econômicos, previsto pela Carta da República de 1988, no tocante à exploração de petróleo offshore, em seu Artigo 20, $\S 1^{\circ}$, mantém, na sua formatação original, uma relação com elementos de natureza tributária e foi desenvolvido a partir da evolução da natureza jurídica da propriedade mineral.

Como anteriormente restou demonstrado, os resultados econômicos da produção de petróleo offshore, mormente aqueles sob a forma de royalties, representam, atualmente, receitas originárias (originárias conforme a classificação das receitas públicas adotada pelo direito financeiro) da União, tendo em vista o caráter de titularidade dominial desse bem e sua utilização por entes de diversos matizes, públicos ou privados, conforme resta definido, no bojo da Carta da República de 1988, em seu Artigo 20, caput e seu inciso V, envolvendo os recursos naturais da plataforma continental e da zona economicamente exclusiva, e seu inciso IX, relativamente aos recursos minerais, inclusive os do subsolo, petróleo em especial.

Em segundo lugar, convém destacar a questão dos resultados econômicos da produção offshore de petróleo e seu modelo de distribuição entre os entes federativos, levando em conta a questão dos componentes tributários.

Três questões merecem destaque, a essa altura, a saber: (a) a federalização das jazidas de petróleo e a consequente perda de receitas tributárias pelos Estados; (b) a definição do monopólio do petróleo constitucional da União e a definição dos resultados econômicos dos Estados e Municípios e (c) a definição do regime especial de tributação do ICMS sobre petróleo e energia elétrica no destino em face de operações com derivados de petróleo. 


\section{A INFLUÊNCIA DA COMPONENTE TRIBUTÁRIA NA DEFINIÇÃO DO MODELO CONSTITUCIONAL DE ATRIBUIÇÃO DOS RESULTADOS ECONÔMICOS NA EXPLORAÇÃ̃O DO PETRÓLEO OFFSHORE NO BRASIL}

A federalização das jazidas de petróleo, iniciada em 1938, quando a matéria relativa ao petróleo passou a ter um tratamento especial, desligado, então, do regime jurídico minerário, que abrangia os demais recursos minerais, trouxe como consequência a perda da propriedade estadual e consequente evasão de receitas para os entes federativos subnacionais.

A perda da propriedade mineral de petróleo pelos Estados e Municípios, tendo em vista a federalização das jazidas de petróleo e a determinação da vedação de jazidas privadas de petróleo, conforme definição do regime especializado de exploração de petróleo criado em 1938, levou à necessidade da criação de uma nova fonte de receita para os entes federativos subnacionais (LOUREIRO, 2012), suprida, no caso, pelo Imposto Único sobre Combustíveis.

É o caso de se destacar o extinto Imposto Único sobre Combustíveis, tributo de competência da União, instituído em 1940, e que deveria, após a devida cobrança, ser devolvido para os Estados e Municípios, compensando, assim, a perda resultante da federalização das jazidas petrolíferas nas mãos da União.

Cria-se um imposto de competência federal, mas na medida em que é devolvido para os Estados e Municípios, figura como um tributo de índole nacional (LOUREIRO, 2012).

Configura-se, assim, que a federalização das jazidas de petróleo, teve como contrapartida um elemento de natureza tributária, qual seja, a criação do Imposto Único sobre Combustíveis, cujo objetivo foi o de atender a questão do desequilíbrio provocado nas receitas derivadas da produção de petróleo em território de Estados produtores.

No que tange à definição do regime do monopólio do petróleo constitucional da União, deve-se levar em conta a questão da atribuição dos royalties decorrentes da produção aos Estados e Municípios produtores, que não obstante não configurem elementos tributários próprios, não deixam de representar receitas originárias que serviram de base para a implementação do regime de concentração das atividades nas mãos da União. Destaque-se, ainda, que a definição do monopólio do petróleo teria se dado após extinção do Imposto Único sobre Combustíveis, provocando, mais uma vez, a necessidade do estabelecimento de medidas compensatórias e que no caso foi a atribuição aos Estados e Municípios de royalties sobre a produção.

Finalmente, no caso específico das reservas de petróleo da área do pré-sal, a definição do modelo de distribuição dos resultados econômicos da exploração offshore, previsto no 


\section{Raymundo Juliano Feitosa \& Marconi Costa Albuquerque}

Artigo 20, $\S 1^{\circ}$, traz à baila um quadro que se sustenta no regime especial da tributação do ICMS com cobrança no destino.

Diferentemente do que muitos procuram estabelecer, qual seja, a definição de resultados econômicos em face de compensação ambiental, ou a definição de resultados econômicos em face de compensação socioambiental, prefere-se aqui vincular a definição dos resultados econômicos decorrentes da produção de petróleo offshore como resultado de uma compensação política (SCAFF, 2014), pela não cobrança de ICMS na origem sobre petróleo e energia elétrica.

\section{CONCLUSÕES}

Em face do que foi exposto, podemos apresentar as seguintes conclusões:

a. o caráter da natureza jurídica da propriedade mineral, definida nos vários textos constitucionais, constitui marco para a definição do modelo de tratamento dos resultados econômicos derivados da produção de petróleo;

b. a publicização e federalização das jazidas e minas de petróleo marca um papel preponderante na definição do modelo de tratamento dos resultados econômicos derivados da produção de petróleo;

c. a definição do modelo de tratamento dos resultados econômicos da produção de petróleo sofre profundo impacto no que tange ao desequilíbrio das receitas tributárias dos entes federativos subnacionais;

d. o regime especial de vedação da cobrança de ICMS na origem de petróleo e energia elétrica constitui um elemento relevante na definição do modelo de distribuição dos resultados econômicos da produção de petróleo offshore. 


\section{A INFLUÊNCIA DA COMPONENTE TRIBUTÁRIA NA DEFINIÇÃO DO MODELO CONSTITUCIONAL DE ATRIBUIÇÃO DOS RESULTADOS ECONÔMICOS NA EXPLORAÇÃ̃O DO PETRÓLEO OFFSHORE NO BRASIL}

\section{REFERÊNCIAS BIBLIOGRÁFICAS}

ANP - Anuário Estatístico Brasileiro do Petróleo, Gás Natural e Biocombustíveis, 2017, http://www.anp.gov.br/wwwanp/images/publicacoes/anuarioestatistico/2017/anuario_2017.pd f, acesso em 18.03.2018.

BALEEIRO, Aliomar. Evolução do imposto único sobre minerais. Revista de Direito Público, $n^{0} 27,1974$.

BAUMAN, Zygmunt. O mal-estar da pós-modernidade / Zygmunt Bauman; tradução Mauro Gama, Cláudia Martinelli Gama, revisão técnica Luiz Carlos Fridman. Rio de Janeiro: Zahar, 1998.

BICHARA, Luiz Gustavo A. S. e MONTENEGRO, Mattheus Reis. In DERZI, Mizabel Abreu Machado; Junior, Onofre Alves Batista; Moreira, Mendes André. Estado Federal e Tributação. Das Origens à Crise Atual. Belo Horizonte, Arraes Editores, 2015.

BRIGAGÃO, Gustavo e LYRA, Bruno. In DERZI, Mizabel Abreu Machado; Junior, Onofre Alves Batista; Moreira, Mendes André. Estado Federal e Tributação. Das Origens à Crise Atual. Belo Horizonte, Arraes Editores, 2015.

COELHO, SACHA CALMON NAVARRO. In DERZI, Mizabel Abreu Machado; Junior, Onofre Alves Batista; Moreira, Mendes André. Estado Federal e Tributação. Das Origens à Crise Atual. Belo Horizonte, Arraes Editores, 2015.

CONSTITUIÇÃO DA REPÚBLICA DE 1988

DERZI, Mizabel Abreu Machado; Junior, Onofre Alves Batista; Moreira, Mendes André. Estado Federal e Tributação. Das Origens à Crise Atual. Belo Horizonte, Arraes Editores, 2015.

FEITOSA, Raymundo Juliano Rêgo. Finanças públicas e tributação na constituinte: 1987/1988. Rio de Janeiro, América Jurídica, 2003.

LOUREIRO, Gustavo Kaercher. Participações Governamentais na Indústria do Petróleo. Porto Alegre, Sérgio Antonio Fabris Editores, 2012.

ROCHA, Lauro Lacerda. Comentários ao Código de Mineração do Brasil. Rio de Janeiro, Forense, 1983.

VIVACQUA, Attilio. A nova política do subsolo e o regime legal das minas. Rio de Janeiro, Panamericana, 